\title{
Opinião
}

\section{RESENHA DO TEXTO: PEDAGOGIAS DIFERENCIADAS - SITUAÇÃO ATUAL}

(PERRENOUD, P. Pedagogia diferenciada: das intenções à ação. Porto Alegre: ARTMED, 2000)

Maria Leomar Macedo (1)

O texto de Pierre Perrenout sobre Pedagogias Diferenciadas: situação atual, tenta apresentar um panorama do que tem acontecido desde os anos 70, em diversas partes do mundo, em termos de práticas pedagógicas diferenciadas. Dada a pluralidade de perspectivas teóricas, e práticas políticas governamentais, o autor reconhece o quão árdua é a tarefa de fazer tal descrição.

Inicia sua análise comentando o quão importante e emergente é a aplicação de psicologias diferenciadas ante as desigualdades sociais e culturais no mundo. Mas ressalta que o fracasso não deve ser visto como uma fatalidade e que há muitas formas de se fazer uma espécie de compensação, de maneira a se conseguir o êxito escolar.

Este tipo de concepção gerou divergências teóricas e protecionismos que provocaram o retardamento dos estudos sobre a pedagogia diferenciada. Dessa forma, a questão fundamental para os professores ainda permanecia sem resposta: como lutar contra o fracasso escolar numa sociedade com características tão desiguais?

A idéia de diferenciação da pedagogia surge como uma opção diante da observação do fracasso escolar observado nos anos 70. Uma das explicações era que o sistema escolar, da forma como se apresentava, reproduzia o sistema de classes e hierarquia social, tornando impossível o combate às desigualdades sociais na escola, mantendo o status quo das classes dominantes.

O desejo de mudanças disseminado pelos governos, bem como as propostas de democratização do ensino, não passavam de uma estratégia para não mudar nada, efetivamente. Os professores, por sua vez, sentiam-se impotentes e ao mesmo tempo culpados por participar de um processo de reprodução das desigualdades sociais, já que todo o desenvolvimento dos programas e métodos já eram concebidos de maneira a manter as 
desigualdades, facilitando o desenvolvimento daquelas classes já mais abastadas e minimizando as chances de desenvolvimento das menos favorecidas socialmente.

Diante dos problemas advindos desse modelo de pensar a educação, como crises políticas e econômicas, os governos no final do século XX retomam a idéia de enfrentamento do fracasso escolar, como uma maneira ética de lidar com a problemática.

A descontinualidade das políticas, a pouca coerência entre intenções e ações democratizantes e o baixo investimento na formação dos professores demonstravam uma tentativa de perpetuação do modelo de reprodução das classes sociais, que ainda se mantinha resistente. Além disso, muitos dos que faziam parte do processo mantinham-se céticos ou indiferentes a possibilidade de mudanças ou de reformas favoráveis a diferenciação do ensino.

O autor, pois, acredita que a pedagogia diferenciada ainda está longe de envolver todos os professores e agentes que fazem o sistema. Contudo, o esclarecimento, as novas práticas metodológicas e o encorajamento de uma avaliação mais formativa, tendem a ampliar o número daqueles que refletem sobre a possibilidade de um tratamento pedagógico cada vez mais personalizado.

Nos últimos trinta anos, tem sido implementado esforços para tornar a estrutura da escolaridade mais flexível, já que a mesma é dividida em etapas anuais com graus, níveis e classes bastante organizados em anos de programas. Dentre essas ações Perrenoud observa algumas:

- Ensino menos formal em cada turma, com formas de avaliação formativa e de trabalhos em subgrupos;

- Abertura entre turmas que seguem o mesmo programa anual, tornando possíveis novos reagrupamentos;

- Reunião em uma mesma turma de alunos que pertencem a anos de programas consecutivos, o que o autor chama de "abertura vertical”;

- A possibilidade de o professor acompanhar o aluno de um grau ao grau seguinte, limitando a reprovação;

- Oferta de opções para dar conta da diversidade de interesses dos alunos;

- Abertura a interventores externos para encarregar-se de alunos com dificuldade;

- Criação e diversificação de pedagogias específicas para crianças com deficiências em seu desenvolvimento;

- Criação de dispositivos para a integração de uma parcela de crianças com dificuldades, em turmas comuns; 
- Criação de estruturas que facilitem a integração e acolhida de crianças recentemente imigradas, não-escolarizadas ou “provisoriamente incapazes” de seguir o ensino numa turma comum;

- Medidas que facilitem ao aluno um progresso mais rápido, quando este demonstrar uma capacidade maior que a média de sua turma;

- Medidas que facilitem a progressão ao grau seguinte durante o ano letivo, caso o professor avalie essa possibilidade em certos alunos.

Essas medidas representam uma flexibilização nas restrições observadas atualmente e possibilidades de uma trajetória mais individualizada por parte dos alunos. Nenhuma delas sozinha daria conta da heterogeneidade dos alunos.

Alguns sistemas educativos inovaram com a criação dos “ciclos de aprendizagem” de dois ou três anos escolares do primeiro grau. Já se comprovou também a possibilidade de se utilizar a idéia dos ciclos no ensino médio, sem reprovações e sem nenhuma forma de seleção intermediária.

A pedagogia diferenciada parece originar uma nova abordagem, mais centrada no educando e mais atenta ao seu itinerário. Essa nova estratégia educacional não resolve todos os problemas didáticos pedagógicos, mas pelo menos cria novas formas de enfrentamento das dificuldades educacionais.

Segundo Perrenoud ainda são muitos os desafios no enfrentamento da pedagogia diferenciada por conta da diversidade de abordagens pedagógicas existentes, que muitas vezes são ambíguas e contraditórias. Mas a proposta é mesmo a de enfrentamento das questões básicas: Como as crianças ou os adolescentes aprendem?Como criar um sentido ao trabalho escolar? Como proteger os educandos das desigualdades e das desordens por que passa a sociedade? Se o aluno encontra-se no centro do processo educativo, como motivar o professor a assumir responsabilidades, como organizador das situações de aprendizagens e, não como distribuidor de saberes?

Todas essas questões alteram a forma de se fazer avaliação. Desse modo, a avaliação formativa parece despontar como imprescindível ao processo educativo quando se pensa em pedagogia diferenciada. A avaliação por essa perspectiva precisa ser de tal forma pensada que ajude o aluno a aprender, sendo parte do seu processo de aprendizagem e não apenas uma medida que o rotule como mais ou menos competente.

Outros autores também abordam a questão da avaliação da aprendizagem escolar, tal como Luckesi, (2000, p. 28), que explicitando o seguinte: 
Importa estarmos cientes de que a avaliação educacional, em geral, e a avaliação da aprendizagem escolar, em particular, são meios e não fins em si mesmas, estando assim delimitadas pela teoria e prática que as circunstancializam. Desse modo, entendemos que a avaliação não se dá nem se dará num vazio conceitual, mas sim dimensionada por um modelo teórico de mundo e de educação, traduzido em prática pedagógica.

Nessa perspectiva, a prática da avaliação escolar não pode ser feita simplesmente de forma medida, calculada, impressa por um valor numérico. Ela precisa estar envolvida de valores construídos pelos homens, buscando um projeto maior de sociedade que atenda os interesses de toda população. Contemplar as diferenças seria também construir um significado de coletividade, de bem estar social a tentar criar situações de aprendizagens que visem práticas associadas às questões políticas e sociais, reverenciando uma pedagogia diferenciada envolvente.

Como afirma Manacorda (1997, p. 360) "nenhuma batalha pedagógica pode ser separada da batalha política e social". Nestes termos, avaliar o aluno requer muito mais.

Outros autores também se referem ao processo avaliativo e ao aluno. Segundo Hoffmann (2002, p.68),

O processo avaliativo não deve estar centrado no entendimento imediato pelo aluno das noções em estudo, ou no entendimento de todos em tempos equivalentes. Essencialmente, porque não há paradas ou retrocessos nos caminhos da aprendizagem. Todos os aprendizes estarão sempre evoluindo, mas em diferentes ritmos e por caminhos singulares e únicos. O olhar do professor precisará abranger a diversidade de traçados, provocando-os a prosseguir sempre.

Observa-se que a essa advertência a respeito dos caminhos da aprendizagem, há que se exigir dos educadores, o cuidado no lidar com o espaço da escola, ajudando o educando a assumir um compromisso pedagógico pessoal, pois,

Educar supõe prestar atenção em nós mesmos: em nossos pensamentos e em nossas ações, bem como na coerência entre eles. Educadores têm de contemplar, portanto, em sua formação inicial e continuada, a busca da sintonia entre o pensar e o viver, o intencional e o gestual. Com certeza estarão buscando, com isto, a sua própria felicidade.

(PONCE, 2000, p. 92) 
A pedagogia diferenciada propõe também um novo paradigma de avaliação, que, segundo Saul (2000, p.61) seria a avaliação emancipatória,

A avaliação emancipatória caracteriza-se como um processo de descrição, análise e crítica de uma dada realidade, visando transformála. Destina-se à avaliação de programas educacionais ou sociais. Ela está situada numa vertente político-pedagógica cujo interesse primordial é emancipador, ou seja, libertador, visando provocar a crítica, de modo a libertar o sujeito de condicionamentos deterministas. O compromisso principal desta avaliação é o de fazer com que as pessoas direta ou indiretamente envolvidas em uma ação educacional escrevam a sua "própria história" e gerem as suas próprias alternativas de ação.

Assim, esse novo tipo de avaliação ao pretender atingir os objetivos do ato educativo necessita estar envolvida em decisões democráticas, acrescidas de senso crítico. A esse respeito, Hoffmann (2002, p. 102), ressalta a importância do significado da avaliação:

Pretendo enunciar que, de fato, a avaliação importa para uma educação libertadora, desde que seu papel não seja o de apresentar verdades autoritárias, mas investigar, problematizar e, principalmente, ampliar perspectivas. Portanto, esse caminho de incertezas e contestações que gradativamente trilhamos em avaliação é um marco significativo em sua história. O descontentamento dos professores com a prática tradicional, classificatória e mantenedora de diferenças sociais é o primeiro passo na direção de uma investigação séria sobre uma perspectiva libertadora da avaliação.

Uma ação educativa voltada à autonomia é necessária, à medida que se inicia com a criança e contempla o jovem e o adulto, oferecendo a eles condições de se tornarem fortes e resistentes. Quando se fala do respeito à 'autonomia do educando', Freire (1996, p. 66) assim esclarece:

Como educador, devo estar constantemente advertido com relação a este respeito que implica igualmente o que devo ter por mim mesmo. Não faz mal repetir a afirmação várias vezes feita neste texto - o inacabamento de que nos tornamos conscientes nos fez seres éticos. $O$ respeito à autonomia e à dignidade de cada um é um imperativo ético $e$ não um favor que podemos ou não conceder uns aos outros.

Cabe então, ao educador, reconhecer que o ato de avaliar, de "educar é antes de tudo mobilizar o aluno para que se torne um aprendiz". (PERRENOUD, 2000, p. 75). 
Quando se refere à pedagogia diferenciada, Perrenoud (2000, p. 9) acrescenta: "Diferenciar o ensino é fazer com que cada aprendiz vivencie, tão freqüentemente quanto possível, situações fecundadas de aprendizagem". Dessa forma, refere-se o autor aos caminhos que deverão ser percorridos pelas avaliações, ferramentas que compõem o processo ensino-aprendizagem, cuja finalidade primeira é a de uma aprendizagem maior, que aponte caminhos na solução de problemas e reinvente maneiras de democratizar o conhecimento.

Essa é a proposta da pedagogia diferenciada na colaboração para com o desenvolvimento das habilidades do educando, priorizando suas atividades enquanto cidadãos numa realidade concreta. Para isso, é importante que se atribua um significado aos conteúdos a serem trabalhados em sala de aula, de forma que o educando tenha maiores possibilidades de aprendizagem e o educador a satisfação de realizar um trabalho com competência.

A docência e a avaliação têm procurado, em grande parte das discussões, definirem o significado de sua prática pedagógica, na educação, levando o educador a considerar que, as inconsistências que hoje se encontram em sua prática educativa são, sem sombra de dúvidas, oriundas de sua formação.

O educador, ao lidar com a avaliação da aprendizagem escolar, deve ter em mente a necessidade de colocar em sua prática diária, novas propostas que visem à melhoria do ensino, pois a avaliação é parte de um processo e não um fim em si e deve ser utilizada como um instrumento, também, para a melhoria da aprendizagem dos educandos.

Perrenoud se refere também ao fato de ser a pedagogia diferenciada pensada como uma abordagem sistêmica que envolve a todos: professores, alunos, família e sociedade. Também que é preciso organizar uma reflexão em torno do paradigma da individualização dos processos de formação, o que inclui também a necessidade de se pensar o papel e a atuação do professor. Que este precisa “reconhecer-se também como responsável pelo insucesso”. Tornar-se capaz de detectar os mecanismos de resistência ainda presentes na sua prática pedagógica evitando a permanência de conteúdos e procedimentos de ensino que não geram resultados eficazes. Segue a isso reconhecer que o insucesso é evitável ao se entender a educação intercultural como uma proposta que requer profundas transformações no conteúdo e na forma de educar, um desapego às verdades pedagógicas tradicionais.

Uma outra questão que o autor coloca é que os professores precisam tentar vencer as inércias e as rotinas de uma ortodoxia pedagógica já superada. As propostas de solução surgem a partir da consciência de que as situações de resistência de alguns alunos estão 
muitas vezes na base de propostas de soluções mais inovadoras e eficazes de ajudá-los em suas dificuldades. Nesse diálogo valoriza todas as parcerias dinâmicas que a instituição possa proporcionar e o trabalho em equipe.

O professor precisa se reconhecer como principal protagonista na sala de aula e colocar-se numa postura de pessoa-recurso, disponível para constantes flexibilizações, contínuas aprendizagens e interações com seus alunos. Deve questionar as possibilidades democráticas de expressão, a participação dos alunos nas iniciativas, no trabalho individual e grupal, e a abertura de toda a turma para o exterior da sala de aula, buscando contínuas aproximações e prazer em lutar coletivamente contra o insucesso.

Perrenoud acredita que, em face da diversidade dos alunos, um professor que desenvolve práticas que contemplam essas especificidades acredita nas vantagens decorrentes delas e transporta para a sala de aula os saberes do cotidiano dos diversos grupos, trabalhando-os, não de forma esporádica e fragmentada, mas contextualizada e vivenciada por processos interativos. Esta atitude educativa imbuirá os professores de uma mentalidade curricular que lhes permitirá ultrapassar o paradigma técnico-burocrático e o peso das rotinas, a fim de conceberem projetos ajustados às realidades em que trabalham.

Assim, para que os professores possam implementar nas suas aulas o princípio da inclusão, terão de possuir conhecimentos sócio-culturais sobre os diversos grupos e serem capazes, também, de utilizar estes conhecimentos na organização curricular e no ensino, de forma a estimular a aprendizagem dos alunos.

Nesse sentido, o educador precisa se inserir no processo educativo dos seus alunos e interagir com todos os outros envolvidos, dialogando com eles e construindo parcerias. A especificidade de sua intervenção educativa consiste dedicar atenção particular às relações e aos contextos que vão se criando, de modo a contribuir para a explicitação e elaboração dos sentidos que os sujeitos constroem e reconstroem a partir da consciência e intencionalidade que dão às suas vidas. 


\section{Conclusão}

A pedagogia diferenciada inclui-se no objetivo da escola, que continua sendo o de oferecer a todos uma cultura básica comum: Sem renunciar à diversificação, seu desafio vai além: conseguir que todos os alunos tenham acesso a essa cultura e dela se apropriem. Considerar as diferenças é, então, colocar cada aluno diante ótimas de aprendizagem. As pedagogias diferenciadas aceitam esse desafio e propõem inovações nas maneiras de resolver o problema. O artigo de Philippe Perrenoud aqui referido aborda aspectos históricos e monta o cenário da situação atual da pedagogia diferenciada. Nele, a idéia principal defendida por Perrenoud é a busca de alternativas de como considerar as diferenças, sem limitar cada aluno em sua singularidade, seu nível e sua cultura de origem.

\section{Referências}

FREIRE, P. Pedagogia da Autonomia: saberes necessários à prática educativa. São Paulo: Paz e Terra. (Coleção Leitura). 1996.

HOFMANN, J. M. L. Avaliação Mediadora: uma prática em construção da pré-escola à Universidade. Porto alegre: educação \& Realidade, 1993.

HOFMANN, J. M. L. Avaliação: Mito \& desafio: uma perspectiva construtivista. 31. ed. Porto Alegre: Mediação, 2002.

HOFMANN, J. M. L. Avaliar para Promover: as setas do caminho. 2. ed. Porto Alegre: Mediação, 2002.

LUCKESI, C. C. Avaliação da Aprendizagem Escolar: estudos e proposições. 10 ed. São Paulo: Cortez, 2000.

MANACORDA, M. A. História da Educação: da antiguidade aos nossos dias. Tradução de Caetano Lo Monoco; revisão da tradução Rosa dos Anjos Oliveira e Paolo Nosella. 6 ed. São Paulo: Cortez. 1997.

PERRENOUD, P. Pedagogia Diferenciada: das intenções à ação. Trad. Patrícia Chittoni Ramos. Porto alegre: Artes Médicas Sul, 2000. 
PONCE, B. J. Um olhar sobre a Ética e o Compromisso. In: Salto para o futuro: Um olhar sobre a escola/ Secretaria de Educação a Distância. Brasília: Ministério da Educação, Seed, 2000.

SAUL, A. M. Avaliação Emancipatória: desafios à teoria e prática de avaliação e reformulação política. 33 ed. Campinas - SP. Autores Associados. (Coleção Polêmicas do Nosso Tempo; v. 5). 2000.

(1) Maria Leomar Macedo é Médica, Professora da Faculdade de Medicina de Juazeiro do Norte-CE e Mestranda em Ciências da Educação pela Universidade de Humanidades e Tecnologias - Lusófona, de Portugal. E-mail: paula_macedo@hotmail.com. 